\title{
Strategic communication and anti-smoking campaigns
}

\author{
JAMES MAHONEY* \\ University of Canberra
}

\begin{abstract}
Worldwide consumer education programs, often fear-based, designed to convince young people to stop cigarette smoking have had mixed success. This paper reviews literature on the effectiveness of anti-smoking campaigns directed at young people and presents findings from research that examined the attitudes of 234 university students towards such campaigns. The research findings, and approaches to strategic communication, are used to argue anti-smoking campaigns might be more effective in generating behavioural change among young smokers if they applied two-way techniques rather than symbolic tactics that characterise current efforts.
\end{abstract}

\section{Introduction}

Anti-cigarette smoking messages, often fear-based, have been directed at people aged 30 and under throughout the western world for most of their lives. Health promotion activities directed at convincing young Australians to avoid or stop smoking have been staged at two levels. First, primary and secondary school health curricula have included direct anti-smoking information in programs such as Triple $\mathrm{T}$ (Teenagers Teaching Teenagers). Second, young people have been exposed to government funded mass media public information campaigns (Grunig, 2001) designed to alert target publics to the dangers of smoking.

Despite this concentration of anti-smoking messages through primary and secondary schools and via the mass media, many young people continue to smoke. In Australia, where anti-smoking school education and mass media campaigns about the health dangers of smoking have been pursued for almost the entire life span of the oldest Gen Y-ers, a significant number of young people report that they have at some time smoked, or still do. In 2006, the Australian Bureau of Statistics reported that while the rate of smoking in Australia had declined slightly from 1995 (when it was $28 \%$ of adults), almost 3.5 million people said they were current smokers $-23 \%$ of all adults (26\% of men and $20 \%$ of women) - in 2004-05. Smoking rates are highest in younger age groups and decline with increasing age (ABS, 2006). The ABS (2006) reported that the highest rate of smoking for men was among those aged 18-24 (34\%) and for women, those aged 25-34 (27\%).

The data suggest that a significant proportion of the population does not heed anti-smoking health messages. In their economic modelling, Bardsley and Olekalns (1999) found that antismoking advertising and education had no significant effect on smoking behaviour, but that workplace smoking bans and health warnings on cigarette packs decreased consumption. They argued that the overwhelming evidence was that of various policy interventions in the 35 years to their research, taxation of tobacco products had been the most effective in reducing aggregate tobacco consumption (Bardsley \& Olekalns, 1999). 
The international literature from research into anti-smoking campaigns raises questions about the effectiveness of publicly-funded fear-based social marketing and suggests a need to consider anti-smoking campaigns in a strategic rather than tactical frame. For example, Miller et al. (2007) noted that no anti-smoking advertising campaign has been an "unqualified success". Gilbert (2005) found that campaigns designed to impact on young women need to adopt strategies that increase the awareness of young people about their own particular health risks. In Hafstad and Aaro's (1997) Norwegian study, smokers reported negative reactions to antismoking campaign messages. Booth-Butterfield (2003) described smoking across a person's life span as a "thoroughly integrated, embedded behaviour" that is difficult to alter, and argued for more focussed communication interventions. Hansen et al. (2010) contend that differential strategies should be applied to warn smokers against negative consequences of smoking as “death-related warnings are not effective". Devlin et al.'s (2007) study of young people in England found that fear-based anti-smoking appeals can encourage a defensive response and ultimately lead to the rejection of messages, especially by committed smokers.

This paper uses key findings from a study of the reasons young people give for smoking, and their attitudes towards anti-smoking messages, to suggest more careful strategic communication campaign planning as one way of addressing the need for effective mechanisms for the promotion of non-smoking (Healy et al., 2000). A strategic approach to anti-smoking public information campaigns should be based on detailed research about how young people receive, process, and act on information.

\section{From the literature}

\section{Smoking}

The focus of worldwide consumer education programs has been on the effects of tobacco use. In order to highlight the leading cause of preventable death worldwide, these programs have largely been fear-based and designed to convince young people to stop cigarette smoking (Fletcher, 2007). Research in Australia and the United States has found that while smoking rates in the general population have declined, those among university students have not (see for example, AIHW, 2002; Tevyaw 2006). Tevyaw (2006) noted that the rate of smoking among people aged 18-24, particularly college students, in the United States was relatively stable and had even increased in the decade to 2006.

In 2002, the Australian Institute of Health and Welfare (AIHW) reported that $15.1 \%$ of Australians aged 14-19 were smokers. Almost a third (31.6\%) of females in that age cohort stated they were daily smokers (AIHW, 2002) - almost double the national average of $16.1 \%$. While the rate of smoking among young women declines during their 20s (to $17.6 \%$, the lowest in Australia), the rate of smoking for young men increases - to 30.1\%, above the national average for the 20-29 years of age cohort. The AIHW (2004) reported that the proportion of daily smokers in the Australian population aged 14 years and over had declined from just under $30 \%$ in 1985 to $17.4 \%$ in 2004 . In $2004,18.6 \%$ of males reported smoking daily compared with $16.3 \%$ of females. In 2006, the ABS reported AIHW data showing that $12.7 \%$ of males aged between 14 and 19 were current smokers, compared with $14.2 \%$ of females. 
Major conclusions of US research (Centres for Disease Control and Prevention) in 1994 were that, among other factors, nearly all first use of tobacco occurs before high school graduation; that most adolescent smokers are addicted to nicotine and report they want to quit but are unable to do so; and that adolescents more likely to smoke were those with lower levels of school achievement, with fewer skills to resist pervasive influences to use tobacco, with friends who smoke, and with lower self images (p. 3).

Studies of the effectiveness of communication campaigns designed to reduce tobacco use among young people are comprehensive and most deal with how young people accept anti-smoking messages. Gilbert (2005) found that campaigns designed to impact on young women need to adopt strategies which increase the awareness of young people about their own particular health risks. Gilbert (2005) argued that it was important to learn from women smokers rather than ignore their 'expertise' and that campaigns should be gender specific "but in ways which do not blame and devalue women and girls" (p. 243). Other studies, Rodger et al. (2005), for example, have examined novel ways of reaching young people with anti-smoking messages - SMS text messages in this case. Hafstad and Aaro (1997) studied the effectiveness of the third consecutive mass media campaign in Norway that used provocative emotional appeals to prevent the onset of smoking among adolescents. This kind of campaign reflects those also used in Australia for delivering both anti-smoking and safe driving messages to young people. Hafstad and Aaro (1997) found that among the 4,994 respondents to their self-administered questionnaire, recall of the non-smoking campaign messages was highest among boys, and that, overall, boys showed the most positive affective reactions. However, smokers in particular reported negative reactions to campaign messages.

Miller et al. (2007) noted that no anti-smoking advertising campaigns have "met with unqualified success" (p. 527). Their research examined whether universal anti-smoking advertisements were optimal for teenagers by comparing adolescents' responses to different print ads across nine culturally diverse countries. Miller et al. (2007) found that individual reactions to the consequences portrayed in anti-smoking advertisements vary by culture. Booth-Butterfield (2002) found that adolescent tobacco smokers felt less in control of their lives in relation to nonusers and, as a consequence of this, may be unable to adapt to anti-smoking communication to achieve positive health outcomes.

In 2003 Booth-Butterfield described smoking across a person's life span as a "thoroughly integrated, embedded behaviour" (p. 171). Factors which led to this were the complexity of the behaviour itself, external situational and socio-cultural factors, and psychological and biological factors related to individual communicators. Booth-Butterfield (2003) noted that it was difficult to alter extensively embedded behaviour. She argued that more focussed communication interventions would result by examining how health-endangering behaviours are embedded among benign or other potentially dangerous behaviours. Investigations of this kind should occur before intervention communication strategies are developed. The current research is one step in such an investigation as it sought to discover why young people may not believe anti-smoking messages, a basic step in the research that should drive the development of an effective communication strategy.

In 2006, Dutta-Bergmann reported on a study of the use of 'soap operas' as a communication tactic for delivering positive health messages. Dutta-Bergmann (2006) argued that formative 
research into the viability of this approach is needed to guide the development of communication strategies. Dutta-Bergmann (2006) argued that health-oriented individuals were more likely to remember health messages in soap operas and incorporate them in future behaviour than were unhealthy individuals.

Campo and Cameron (2006) examined the use of 'social norms' campaigns to investigate university students' processing of anti-drinking messages. They found that such campaigns did generate a slight attitudinal shift, but not always in a positive direction. Zhao et al. (2006) had similar findings, although in this case mostly slightly positive, from their study which looked at behavioural change after adolescents were exposed to three anti-marijuana use advertisements. Stephenson et al. (2002) found that, among other factors, exposure to friends and family who used marijuana resulted in greater use of the drug by younger adolescents and suggested that this had implications for the design of future anti-marijuana messages. Ferguson et al. (1992) investigated predictors of recruiting others to smoke cigarettes among 273 seventh grade students who had smoked at least once. Ferguson et al. (1994) found that significant predictors of recruiting others to smoke include best friend (same sex) smokes, number of same-sex friends who smoke, and perceived positive consequences of smoking.

Brannstrom and Lindblad (1994) investigated the extent to which five years of exposure to news media messages affected the health of 16-80 year olds in an intervention area in Sweden. They found that sex and social class in people recalling messages and 'ordinary people' who delivered messages were seen as exemplars. Pinkleton et al. (2007) studied the effectiveness of a media literacy curriculum on tobacco use among 723 adolescents. They found that media literacy had a positive effect on reflective thinking about tobacco use, whether or not the participants had smoked tobacco.

Audrain-McGovern et al. (2003) argued from the results of their study of receptivity to tobacco advertising among 1071 high school freshmen, that counter-advertising messages should consider individual differences in novelty seeking because young people thus categorised were more receptive to tobacco industry campaigns. Similar findings are reported from research by, for example, Adelman (2001), Cummings et al. (1997), Etter et al. (2003), Pingree et al. (2004), Sussman et al. (2001 and 2006) and Rodgers et al. (2005).

In a study related to the present research, Hansen, Winzeler and Topolinski (2010) used terror management theory to examine the impact of anti-smoking messages in cigarette package labelling in the context of self-esteem and mortality-salient warnings. They found that warning messages on cigarette packages can be effective in inducing anti-smoking attitudes. However, they found a link between smoking and self-esteem which suggested that fear-based warnings may not be heeded by those who based their self-esteem on smoking. Hansen et al. (2010) argued that a differential strategy should be applied to warn smokers against negative consequences of smoking (p. 228). They found that death-related warnings "are not effective and even have unwanted effects when smokers have a high smoking-based self-esteem" (p. 228). In their view, young smokers who want to impress their peers may base their self-esteem on smoking to a higher degree than others. Hansen et al. (2010) suggest that such populations should be warned against noxious consequences of smoking with death-neutral messages that undermine their smoking-based self-esteem. Their research found that "when smokers are faced 
with death-related anti-smoking messages on cigarette packs, they produce active coping attempts as reflected in their willingness to continue the risky smoking behaviour" (p. 228).

Devlin et al. (2007) found from their study involving young people in England that fear-based anti-smoking appeals can encourage a defensive response and "ultimately rejection of the message, particularly among more committed smokers". Such appeals were likely to be effective only when combined appropriate forms of advice and support with the efficacy components of messages being designed to specifically meet the needs of young people (Devlin, et al., 2007).

\section{Strategic communication}

Hallahan et al. (2007) defined strategic communication as the "purposeful use of communication by an organisation to fulfil its mission" and note that

Strategic communication differs from integrated communication because its focus is how an organization communicates across organizational endeavours. The emphasis is on the strategic application of communication and how an organisation functions as a social actor to advance its mission. (p. 7)

In their view, strategic communication "is about informational, persuasive, discursive, as well as relational communication when used in a context of the achievement of an organisation's mission" (p. 17).

Sandhu (2009) described strategic communication as multidisciplinary 'intentional' communication that requires a purposeful actor, and rational and deliberate decision-making. J.E. Grunig (2006) argues that strategic communication is a 'bridging activity' between organisations and their stakeholders that should be standard procedure, that is, institutionalised. That reflects the notion of two-way symmetrical communication (see, for example, Grunig 2001), the practical applications of which Lane (2007) has argued are insufficiently considered by scholars and practitioners. Argenti, Howell and Beck (2005) defined strategic communication as being "aligned with the company's overall strategy, to enhance its strategic positioning" (p. 83). They noted that strategic communication must have a long-term orientation in which practitioners must "meet short-term needs by stay focused on the long-term issues' facing organisations ( $p$. 89). Zerfass and Huck (2007) argue that strategic communication 'prepares organisations for an uncertain future" (p. 108) Cornelissen (2005) notes that the scope and involvement of strategic communication as a management function becomes more substantial when it stretches beyond a set of functional goals and tactics to corporate and business unit levels. In its critical management function, strategic communication practitioners thus need to respond to a business needs and concerns (Cornelissen, 2005).

Among communication management functions described by Van Ruler and Verčič (cited in Tench et al. 2009) are

- counselling the members of an organisation on matters of values, norms and issues important to society;

- coaching the members of an organisation to respond communicatively to societal demands; and 
- conceptualising and planning communication with important publics to gain public trust.

Argenti et al. (2005) posit three drivers of strategic communication: regulatory factors, organisational complexity, and the need to increase credibility. Cornelissen (2005) notes that as a strategic management function communication is "charged with counselling senior management, and guiding and managing reputations and relationships with important stakeholder groups" (p. 100). Strategic communicators' concerns with communication disciplines and their associated tactics are directed at how they advance top-level strategic goals and objectives, rather than in implementing tactics (Cornelissen, 2005).

Grunig's (2009) discussion of two paradigms for public relations practice provides a further view of strategic communication as it relates to campaigns designed to generate behavioural outcomes. Grunig (2009) argues that practitioners working in the "symbolic, interpretive" paradigm of marketing communication "generally" believe publics can be persuaded by messages that change their cognitive representations. This approach, he argues, devotes excessive attention to the tactical role of communication in negotiating meaning by emphasising messages, publicity, media relations and media effects (Grunig, 2009). A contrasting "strategic management, behavioural" paradigm builds relationships with stakeholders (Grunig, 2009). This paradigm facilitates two-way communication and dialogue and includes a framework of research and listening, as a result of which "messages reflect the information needs of publics as well as the advocacy needs of organisations" (Grunig, 2009, p. 9).

This brief overview of literature related to anti-smoking campaigns directed at young people, and of the principles of strategic communication, suggests that professional communicators may need to more carefully design campaigns to take account of the ways in which young people receive and process health information. The literature on the growing field of strategic communication provides some direction for organisations promoting positive behavioural outcomes.

\section{Methodology}

The study was designed to identify awareness, and acceptance, of anti-smoking messages by young people, especially public information (J.E. Grunig, 2001) campaigns that use fear based messages. The study involved 234 first, second and third year students studying advertising and marketing communication, journalism and public relations. The self-administered questionnaire sought quantitative and qualitative data. Likert scale type questions collected quantitative data about awareness of anti-smoking messages and attitudes towards them, smoking behaviour and reasons for smoking, as well as demographic information including, for example, age, and gender. Respondents were asked to provide qualitative answers to questions about their recall of anti-smoking messages, reasons for accepting or rejecting those messages, the nature of information provided by teachers, and whether they believed messages from teachers. The research, funded by the health promotion unit of the ACT Department of Health, was approved by the University of Canberra's Committee for Ethics in Human Research.

Questionnaires were administered during the first 10 minutes of normal weekly tutorials. Students were given an information sheet that explained the purposes of the investigation, that their responses would be kept confidential, that they were not being asked to provide personal information that would identify them individually or by their tutorial group, that participation 
was voluntary, and information about what they should do if they felt uneasy answering questions. It also advised them that the study had human ethics committee approval. Students were advised by their tutors, and in the information sheet, that they could withdraw from answering the questionnaire at any time. Students personally placed their completed questionnaires in an unidentified envelope, which as sealed after all questionnaires were submitted. The information sheet invited respondents to give their name and address if they wished a copy of the final report to be sent to them. Information sheets from students who requested a copy of the report were collected separately from completed questionnaires.

Survey responses were recorded on a FileMaker Pro database and statistical calculations were made with an Excel spreadsheet.

\section{Results}

The majority of respondents, $74.8 \%(\mathrm{n}=176)$, were female. Almost two-thirds of 234 respondents $(64.5 \%, \mathrm{n}=151)$ had smoked at one time (66\% of males and $64 \%$ of females). Only $36 \%(\mathrm{n}=55)$ still smoke: fewer females (34\%) than males (42\%) who have smoked say they continue to smoke.

All respondents accept that smoking may harm their health, reflecting the findings of a number of previous studies (for example, Healy, et al., 2000; Gilbert, 2005). However, recognition of the message has not deterred some people from continuing to smoke: the most common reasons given for continuing the habit are that they enjoy it, they cannot quit, smoking relaxes them, or their friends smoke.

Almost all respondents (97\%) recall hearing or seeing anti-smoking advertisements on radio and television. Just over half (56\%) recall anti-smoking messages delivered at school. Most respondents (98\%) believed anti-smoking messages, although one male (age: 22-24) said, about anti-smoking messages, in the comments section of the questionnaire, 'I refuse to believe.' Males and females differ on which anti-smoking message delivery mechanisms (channels) they would believe. For all respondents, smokers and non-smokers, females rated messages delivered by 'medical people' as their 1 st preference ( $91 \%$ of females, $n=160)$, while males regarded this as their second priority $(85 \%, \mathrm{n}=49)$ after electronic advertising $(90 \%, \mathrm{n}=52)$. See Table 1 for rankings. Current male smokers rated messages on cigarette packs as their second preference ( $81 \%$ of current smokers, $n=13$ ) after radio and television advertising (94\% of current smokers, $\mathrm{n}=15)$. Fear-based messages are less likely to be believed by males $(57 \%$ of the total, $\mathrm{n}=34)$ than by females $(70 \%, n=122)$. Overall, anti-smoking messages on cigarette packages $(81 \%$ of the total of box sexes, $\mathrm{n}=191)$ rate higher than messages delivered by parents $(69 \%, \mathrm{n}=162)$ or friends $(67 \%, \mathrm{n}=157)$. Male smokers rate peer group interactions and advice from doctors as their equal third choice $(75 \%, \mathrm{n}=12)$.

\section{When people started smoking}

Most respondents who have ever smoked $(\mathrm{n}=145)$ started between 13 and 17 years of age $(71 \%)$. Most females who have ever smoked (68.2\%) stated between 13 and 17 years of age as did $79.4 \%$ of males. A higher proportion of females (28.2\%) who have ever smoked began smoking between 18 and 21 than did males $(11.8 \%)$. 


\section{The sample's smoking habits}

Of those smokers who answered the question about how many cigarettes they smoked in a day (20 smokers did not answer), 68.6\% ( $n=22)$ smoke between one and five cigarettes a day; nine smoke between 11 and 15 a day. More females than males smoke between one and five cigarettes a day, and twice as many males were more likely to smoke between 11 and 15 cigarettes a day - a finding that may not be statistically significant given that not all smokers answered this question.

\section{Reasons for smoking}

No respondent gave 'I do not believe health warnings', or 'I do not think it will harm my health' as reasons for smoking. The most common reason given for smoking - among both current smokers and those who have previously smoked - was 'Because I enjoy it.' Almost half smokers $(n=26)$ gave this reason; 16 were female. Females who enjoy smoking comprised $29 \%$ of all smokers and males $18 \%$. The second most common reason given for smoking was 'I cannot give it up.' Of the 10 smokers who gave this reason, six were female. The third most common reason for smoking, including for those who have stopped, was, 'All my friends smoke.' Of current smokers who gave this reason $(n=12)$, eight were female.

Of current smokers $(n=55)$, one fifth say smoking not only relaxes them but that they enjoy it $(n=11)$. Of these smokers, five also say that they cannot give up cigarette smoking. More than half of smokers in the sample $(58 \%, \mathrm{n}=32)$ said they smoked when they were busy or stressed; $55.3 \%$ of female smokers and $63 \%$ of male smokers gave this response. Being busy or stressed was not a factor in the smoking habits of $20 \%$ of smokers. A further $20 \%$ of smokers said that being busy or stressed varied as a factor in whether they would smoke at any given time.

A group of 20 smokers did not answer how many cigarettes they smoked each day. Of those who did answer, and who also say they smoke when they are busy or stressed, $44 \%$ smoke between one and five cigarettes a day, and 19\% smoke between 11 and 15 a day.

\section{Recalling anti-smoking messages}

Respondents were asked questions about their recall of two ways of delivering anti-smoking communication: advertisements on radio and television, and talks from teachers. They were also asked to write down the main message or messages they recalled from advertising and from teachers. More remembered the advertisements than recalled talks by teachers.

Almost all respondents (97\%, $\mathrm{n}=227$, total number who answered this question=233) recall hearing or seeing anti-smoking advertisements. Just over half $(56 \%, \mathrm{n}=122)$ recall their teachers talking about smoking. Their recollections of messages included 'smoking kills,' 'if you smoke you will die,' 'every cigarette does you damage,' and 'gives you lung cancer.' Of those who said they recalled hearing or seeing anti-smoking advertisements, 98\% ( $n=226)$ said they believed the messages. Females comprised $74 \%(n=169)$ of this group and males $23 \%(n=53)$. 
Females who heard and believed anti-smoking messages comprised $73 \%$ of the total sample, and $74 \%$ of those who believed the messages; $23 \%$ of the total sample, and who believed messages, were males (one student did not answer these questions).

\section{Teachers talking about smoking}

More than half the respondents $(55.8 \%, \mathrm{n}=130$, total number who answered this question=233) recalled hearing teachers talk about smoking. Almost all those who recall teachers talking about smoking (94\%), believed the messages. Just over a quarter of respondents said they could not recall their teachers talking about smoking. However, almost a third of this group said they believed anti-smoking messages anyway. Fewer respondents did not recall teachers talking about smoking $(\mathrm{n}=42)$.

\section{Smokers' recall of anti-smoking messages}

Of those respondents who still smoke $(n=55)$, five wrote qualitative comments noting that the main messages they heard from advertisements and teachers was that smoking was bad for a person's health. So, why do they smoke? One smoked because all their friends did; two because they enjoy it; one could not give up; and one gave all three of the main reasons for smoking: cannot give, enjoy it and it relaxes them. All were in the 19-24 age group, four were female.

\section{Information delivery mechanisms smokers would believe}

A male smoker (22-24 age group) who did not believe anti-smoking messages said people "don't believe it 'cause they haven't seen it in real life". A non-smoking male in the same age group said he didn't "really remember" but mostly "saw them on cigarette boxes".

Respondents were given a list of eight possible message delivery mechanisms, which included advertising, messages on cigarette packages, advice from doctors or discussions with friends. They were asked to indicate whether they would believe, or would not believe, anti-smoking messages delivered by each of the eight delivery mechanisms. The results were ranked according to the percentages of respondents who answered 'Yes' to whether they would believe messages delivered by each of the mechanisms. Rankings were calculated for all respondents and for current smokers. In each category, rankings were calculated for males and females. See Table 1 for details.

For all respondents, and among smokers, females are more likely to believe messages delivered by medical people like doctors, while males are more likely to believe messages they see or hear in television and radio advertisements. Among smokers, 'messages on cigarette packages' is the second most 'believable' mechanism (equal with 'signs and posters' for male smokers), but this mechanism rated third in the total sample. Anti-smoking messages designed to scare people are the least 'believable' mechanism among the total group - and always the least 'believable' among males. For female smokers, messages that are designed to scare people rate as the third most believable message delivery mechanism. Male smokers rate medical advice, and information or discussions with friends, as the third most believable message delivery mechanism. These results suggest that anti-smoking messages may have greater success if they were designed to respect young people's needs and preferences and delivered via channels that 
target publics prefer (Guth \& Marsh, 2006). In this way messages would have what Guth and Marsh (2006) describe as a 'tactical value'. Gregory's (2009) view that messages indicate oneway communication but initiate dialogue that is often undervalued, supports this approach. Poorly conceived messages, perhaps those designed to scare people about the effects of smoking, and delivery channels that do not suit the preferences of target publics could be a reason that communication about this issue is not effective and may be wasted (Gregory, 2009). As Gregory (2006) notes "Carefully thought-through content is vital to understanding and dialogue" (p. 187)

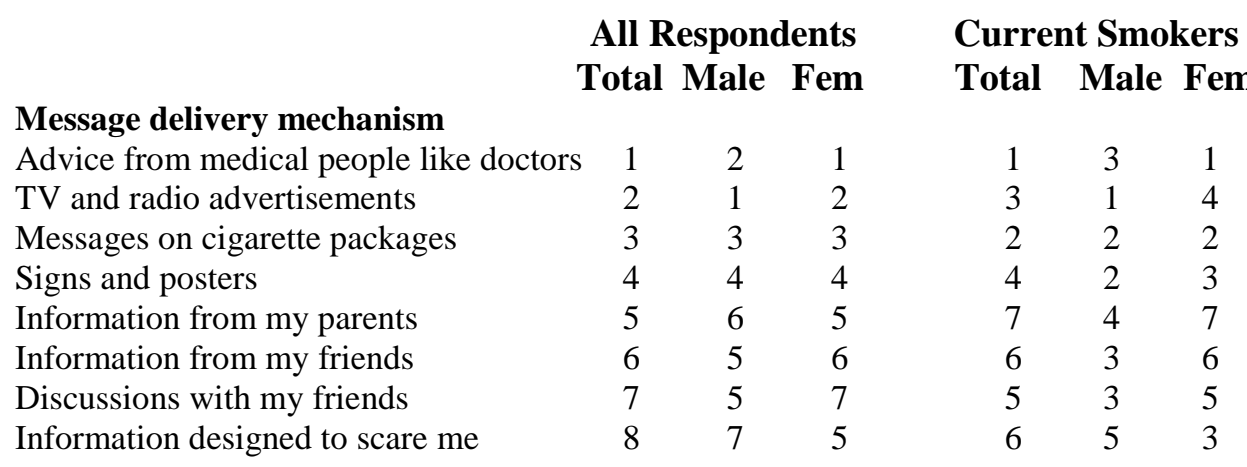

Table 1: Ranking of anti-smoking message delivery mechanisms

\section{Discussion}

The research results reflect previous Australian data that showed males are more likely than females to continue smoking during their twenties (Australian Institute of Health and Welfare, 2001; ABS, 2006). Some respondents consider themselves 'social smokers' but describe themselves as 'non-smokers' because they only smoke cigarettes when they are drinking.

\section{Believing messages}

The overwhelming majority of respondents have seen or heard anti-smoking messages and say they believe those messages - only six said they did not, but none gave this as a reason for smoking. All accept that cigarette smoking is risky behaviour that could damage their health, and most of those who smoke say their think about cutting or cutting down daily or once or twice a week.

Radio and television advertising appears to have been a more successful mechanism for delivering anti-smoking messages than have attempts by teachers and parents to convince young people to stop smoking, or not take it up. More respondents recalled radio and television advertising than messages delivered by teachers. Qualitative comments suggested that teachers were not believed because many of them smoked anyway. The study found a consistent difference in responses to questions about the effectiveness of anti-smoking messages between males and females. Advertising appears to work best with males and medical advice to work best with females. This finding applies whether a respondent smoke or do not smoke. Females rate advertising as the fourth most believable mechanism.

This study suggests that traditional anti-smoking scare campaigns may not be working effectively with young people. The study found that messages designed to scare young people 
from smoking do not appear to impact on male smokers at the same level as they do on female smokers. One respondent, who only smokes when drinking, said of messages designed to scare people, "Most of my friends that smoke don't care about ads that use shock tactics". It may be that fear works more effectively on females because femles assess health information more rationally than males via 'central route' processing (Gabbott and Clulow, 1999, see below). Females' rating of face-to-face interaction with doctors and other medical people as their preferred way of receiving anti-smoking messages supports this.

The findings suggest that cognitive dissonance may help to explain young smokers' behaviour: they understand that smoking is bad for their health, and that it may kill them, but smoke anyway. Qualitative responses that fear-based messages 'don't work' and that people do not believe these messages because "they haven't seen it [health consequences] in real life" support Hafstad and Aaro's (1997) findings young smokers have negative reactions to anti-smoking messages. That also helps to explain why, among the total cohort, messages designed to scare people rated last as a mechanism students would believe. Additionally, people say they smoke for reasons not related to their awareness and acceptance of health-impact messages.

Implications of these findings for strategic campaign design are discussed below.

\section{Some possible theoretical approaches}

While the findings may not be generalisable, they do suggest that public information programs designed to deliver anti-smoking messages targeted at young people have had mixed success. There appear to be two principal reasons for this:

1. Fear-based messages are ignored; and

2. Strategies and tactics may not have adequately taken account of the ways in which young people process information.

Thus anti-smoking campaigns may need to be based on more detailed research that tests how young people actually process, and act on, messages. This suggests that anti-smoking campaigns need to be more precisely targeted and that messages, and message delivery strategies, should be more carefully planned. In short, a 'one size fits all' approach may not be appropriate.

How might campaign improvements be made? As a starting point, health promotion strategists might use elements of content and process communication theories to inform their formative research for campaign situation analyses and campaign design. Content theories, for example McClelland's acquired needs theory, assist in profiling the 'needs' that motivate an individual's behaviours. Process theories, for example Vroom's expectancy theory, suggest ways of examining how an individual's behaviour is influenced by cognitive processes.

McClelland's acquired needs theory suggests that individuals are motivated by three underlying needs: for achievement, affiliation and power. The theory is generally applied in a work environment where 'needs' can be associated with different work roles and can be used by managers to create work environments that respond to the need profiles of individual employees (Wood et al., 2004). Nevertheless, the theory has application in anti-smoking campaigns. For example, McClelland suggested that people with a high need for achievement prefer individual responsibility and challenging but achievable goals. Those with a 'high affiliation need' prefer 
interpersonal relationships and opportunities to communicate. People who are motivated by a high need for power, seek influence over others and recognition (Wood, et al., 2004). Research for campaign situation analyses could investigate how such 'needs' can be applied in the design and delivery of anti-smoking messages. How, for example, might a need for high affiliation be applied to messages designed to reach young people who smoke because their peer group smokes?

Vroom proposed an 'Expectancy Theory' to suggest that individuals somehow calculate the benefits behaving in certain ways, or do what they can when they want to (Wood, et. al., 2004). Individuals place a value, or 'valence', on, for example, work outcomes after they assess the effort, or 'expectancy', involved in performing a task and the probability that performing the task, or 'instrumentality', will lead to a rewarding outcome. The theory suggests that people's beliefs about effort and performance relationships, and the desirability of outcomes, determine motivation. Anti-smoking messages appear to apply elements of this theory. However, identifying ways in which young people who say they smoke because it 'relaxes them' can be convinced to more effectively calculate the 'zero valence' of smoking may be an area for further investigation by scholars and strategic health communicators.

In 1983, Petty and Cacioppo proposed that people process, or elaborate on, information in two ways: via peripheral cues or by careful and thoughtful consideration. They described the first processing mechanism as the 'peripheral route' and the second as 'central route' (Gabbot \& Clulow, 1999). The key point of their 'Elaboration Likelihood Model' is that it explains how people might be persuaded to take a new attitudinal position that may conflict with an attitude they already hold (Gabbot \& Clulow, 1999). To do that people rely on the credibility of those giving messages and they are affected by whether there is a consensus among those around them that supports messages. 'Central route' processing occurs when an individual elaborates a message by carefully considering the merits of information and reaches an evaluated conclusion (Gabbot \& Clulow, 1991). An individual who processes information via the 'peripheral route' relies on peripheral cues. This occurs when the ability, or motivation, to elaborate a persuasive message is low. Gabbot and Clulow (1991) argue that the two most important task-related variables on the motivation to elaborate are the personal relevance of a message and the perceived responsibility for evaluating the message's recommendation. They argue that the 'key' point about the model is that it's about persuading people of a new attitudinal position which "may often conflict with an attitude already held" (p. 179). This model suggests the need for greater care in the selection of anti-smoking message delivery strategies, especially for how messages might be written to meet rational decision-making and responsibility criteria. The study's finding that women are more likely to listen to anti-smoking messages from doctors suggests that they might process messages in a more rational, perhaps personal and highly involved, way than males. Thus, doctors may be a more credible source of information for them than other sources. Might males react more effectively to credible role models in electronic advertising than they appear to react to fear-based messages that do not employ such role models?

These theoretical approaches have practical implications for campaign goal and objective setting, the design of messages that relate specifically to target publics (Gregory, 2009) and the ways in which they process information (Gabbot \& Clulow, 1991). For example, campaigns applying differential strategies (Hansen et al., 2010) for male and females based on the ways in which they 
prefer to receive information, and the different ways in which they process messages, may be more effective than current generalist approaches. The credibility of spokespeople used in antismoking campaigns is a critical consideration the selection of appropriate channels for reaching specific target publics, and the associated campaign tactics - the collateral that actually contains messages. The present research suggests doctors are a credible source of information for females, and to a lesser extent for males. Placing greater emphasis on using doctors and other medical people like nurses in a face-to-face communication message delivery strategy would reflect Grunig's (2009) strategic management, behavioural paradigm and implement effective two-way symmetrical communication. This would avoid the symbolic, interpretive paradigm (Grunig, 2009) of previous anti-smoking campaigns that relied on marketing communication approaches in which protagonists emphasise messages at the expensive of dialogue.

\section{Limitations of the study}

It may not be possible to generalise the results of this study to the broader age population. First, all participants were university students and thus had a level of educational achievement that might not be reflected in the wider population. Second, all respondents were studying communication-related disciplines and could be expected to be more aware of (a) the public discourses about smoking and (b) to communication campaign development and implementation than might other students, or young people in these age groups in the wider community. Third, the study was commissioned by the ACT Department of Health's health promotion unit and the research was limited to university students on one campus. The cohort included students who grew up in Canberra as well as others who live in Canberra only because it is their place of tertiary study. In addition, 35 international students responded. Thus the results may not be generalisable to the wider Australian university student population if there were differences in anti-smoking campaigns, especially the frequency with which the issue was addressed, between Australian jurisdictions and those experienced by international students.

The survey instrument did not ask whether people only smoked when they were in different social situations such as drinking with friends, or when they were 'drunk.' Some respondents referred to this omission in their qualitative comments and were uncertain whether they should describe themselves as smokers if this was their experience. While this does not appear to have been a major issue with respondents, a question about smoking in a range of social contexts may have produced a different, and perhaps more accurate, result on the number of respondents who regard themselves as smokers. A few respondents said that they found the survey structure difficult, especially two non-smokers who wanted to give additional qualitative comments although both did actually comment. However, a revision of the survey structure to specifically seek comments from smokers and non-smokers may have enhanced the findings. Finally, a more detailed exploration of the topic through a series of focus groups would have enhanced qualitative interpretation of attitudes towards anti-smoking health messages.

\section{Conclusion}

Health promotion strategists have a tough job to convince young people to quit smoking - or to avoid starting. The problem strategists face is not that young people reject health-based antismoking messages; it is that young people smoke for more entrenched, perhaps less rational, reasons - they cannot give up, they believe it relaxes them, or their friends smoke. In addition, 
young people are specific, sometimes a touch cynical, about the methods by which they prefer to receive anti-smoking messages and which they would believe. One female non-smoker (19-21 age group) said, for example, that signs and posters would be more effective is they were in credible places like a doctor's surgery. Another female non-smoker (same age group) stressed that anti-smoking campaigns should focus of short-term effects because the long-term effects used in advertising "are too far away and unlikely for young people".

The task for health promotion strategists is to find messages, delivery strategies and tactics that address these issues and appropriately match them to clearly identified target publics. Healy et al. (2000) argued a similar point on the basis of their research. Their research indicated that "greater attention needs to be given to verifying and using appropriate communication channels for youth" (p. 152).

Strategic communication theory suggests that future anti-smoking public information programs for young people should reflect the different ways in which males and females prefer to receive messages. Anti-smoking information should be prepared and presented in ways that address the needs of young people, and the reasons they smoke, rather than to persuade by attempts to scare them into action and different approaches for males and females appear to be necessary. The research reported here suggests greater use of interpersonal two-way communication in future anti-smoking programs, especially by formally involving doctors and other medical professionals. Interpersonal approaches involving two-way communication strategies may improve anti-smoking campaign effectiveness. The research results discussed here also suggest that spokespeople for anti-smoking campaigns directed at young people should be regarded by publics as professional and credible. Finally, message delivery strategies, including interpersonal communication, and tactics should be based on research that tests the effectiveness of messages designed for specific target publics, and how they can be best delivered.

Miller et al. (2007) argued that the waste of money inherent in ineffectively designed advertising was obvious as behavioural changes were not achieved and the costs were possibly for nought. While anti-smoking campaigns designed as proposed in this paper may be more expensive than the current approach, and take longer to implement, they will have a better chance of delivering more positive results. They certainly would not deliver instant impressions that something is being done about an urgent health issue. But they have a better chance of being more effective than fear-based campaigns that research consistently suggests are not generally effective.

\section{References}

Adelman, W.P., Duggan, A.K., Hauptman, P. \& Joffe, A. (2001). Effectiveness of a high school smoking cessation program, Pediatrics, 107(4): E 50.

Argenti, P.A., Howell, R. A., and Beck, K.A. (2005). The Strategic Communication Imperative, MIT Sloan Management Review, 46(3), 82-89.

Audrain-McGovern, J., Tercyak, K.P., Shields, A.E., Bush, A., Espinel, C.F. \& Lerman, C. (2003). Which adolescents are most receptive to tobacco industry marketing? Implications for counteradvertising campaigns. Health Communication, 15(4), 499-513.

Australian Bureau of Statistics. (2006). 4831.0.55.001 - Tobacco Smoking in Australia: A Snapshot, 2004-05. Retrieved from http://www.abs.gov.au/ausstats/abs@nsf/mf/

4831.0.55.001. 
Australian Institute of Health and Welfare. (2002). 2001 National drug strategy, household survey: Detailed findings. AIHW cat. No. PHE 41. Canberra: AIHW (Drug Statistics Series No. 11).

Bardsley, P., \& Olekalns, N. (1999). The impact of anti-smoking policies on tobacco consumption in Australia. Health Promotion Journal of Australia, 9(3), 202-205.

Booth-Butterfield, M. (2000). Adolescents' use of tobacco, health locus of control, and self-monitoring. Health Communication, 12(2), 137-148.

Booth-Butterfield, M. (2003). Embedded health behaviours from adolescence to adulthood: The impact of tobacco, Health Communication, 15(2), 171-184.

Brannstrom, I. \& Lindblad, I-B. (1994). Mass communication and health promotion: The power of the media and public opinion. Health Communication, 6(1), 21-36.

Cornelissen, J. (2005). Corporate communications: Theory and practice. London: Sage.

Cummings, K.M., Hyland, A., Pechacek, T.F., Oralandi, M. \& Lynn, W.R. (1997). Comparison of recent trends in adolescent and adult cigarette smoking behaviour and brand preferences, Tobacco Control, 6, Suppl. 2: S31-37.

Devlin, E., Eadie, D., Stead, M., and Evans, K. (2007). Comparative study of young people's response to anti-smoking messages. International Journal of Advertising, 26(1), 99-108.

Dutta-Bergman, M. J. (2006). A formative approach to strategic message targeting through soap operas: Using selective processing theories, Health Communication, 19(1), 11-18.

Etter, J.F., le Houezec, J. \& Landfeldt, B. (2003). Impact of messages on concomitant use of nicotine replacement therapy and cigarettes: A randomised trial in the Internet, Addiction, 98(7), 941-950.

Ferguson, K.J., Burke, J.A., Becker, S.L., Reimers, T.M, Daughety, V.S. \& Pomrehn, P.R. (1992). The recruitment of new smokers by adolescents, Health Communication, 4(3), 171-181.

Gabbot, M., and Clulow, V. (1999). The elaboration likelihood model of persuasive communication. In P. Kitchen (Ed.). Marketing communications: Principles and practice(pp.172-188). London: International Thomson Business Press.

Gilbert, E. (2005). Contextualising the medical risks of cigarette smoking: Australia young women's perceptions of anti-smoking campaigns, Health, Risk \& Society, 7(3), pp. 227-245.

Gregory, A. (2009). Public relations as planned communication. In R. Tench \& L. Yeomans (Eds.). Exploring public relations ( $2^{\text {nd }}$ ed.) (pp.174-197). Harlow, England: Prentice Hall.

Grunig, J. E. (2009). Paradigms of global public relations in an age of digitalisation. Prism, 6(2), http://praxis.massey.ac.nz/fileadmin/Praxis/Files/globalPR/GRUNIG.pdf.

Grunig, J.E. (2006). Furnishing the edifice: Ongoing research on public relations as a strategic management function. Journal of Public Relations Research, 18(2), 151-176.

Grunig, J. E. (2001). Two-way symmetrical public relations: Past, present, and future. In R. L. Heath (ed.). Handbook of public relations (pp.11-30). Thousand Oaks, CA: Sage.

Grunig, J.E. \& Repper, F.C. (1992). Strategic management, publics, and issues. In J.E. Grunig, (Ed.). Excellence in public relations and communication management (pp. 109-116). Hillside, NJ: Lawrence Erlbaum Associates.

Guth, D.W. \& Marsh, C. (2006) Public relations: A values-driven approach (3 ${ }^{\text {rd }}$ ed.). Boston, MA: Pearson Education.

Hafstad, A., \& Aaro, L.E. (1997). Activating interpersonal influence through provocative appeals: Evaluation of a mass media-based antismoking campaign targeting adolescents, Health Communication, 9(3), 253-272.

Hallahan, K., Holtzhausen, D., Van Ruler, B., Verčič, D. \& Siramesh, K. (2007). Defining strategic communication. International Journal of Strategic Communication, 1(1), 3-35.

Hansen, J., Winzeler, S., \& Topolinski, S. (2010). When the death makes you smoke: A terror management perspective on the effectiveness of cigarette on-pack warnings. Journal of Experimental Social Psychology, 46(1), 226-228.

Healy, G. N., Stanton, W. R., and Silva, P. A. (2000). Adolescent influences not to smoke, and recall of anti-smoking campaigns. Health Promotion Journal of Australia, 10(2), 148-153. 
Lane, A. (2007). Empowering publics: The potential and challenge for public relations practitioners in creative approaches to two-way symmetric public relations. Australian Journal of Communication, 34(1), 71-86.

Mahoney, J. \& Burrell, A. (2007). A puff of smoke: The effectiveness of anti-smoking campaigns among young Canberrans. University of Canberra pilot research study for the ACT Department of Health.

Miller, C., Foubert, B., Reardon, J. \& Vida, I. (2007). Teenagers' response to self- and other-directed anti-smoking messages: a cross-cultural study. International Journal of Market Research, 49(4), 515-543.

Miller, C. H., Burgoon, M., Grandpre, J. R. \& Alvaro, E. M. (2006). Identifying principal risk factors for the initiation of adolescent smoking behaviours: The significance of psychological reactance. Health Communication, 19(3), 241-252.

Pingree, S., Boberg, E., Patten, C., Offord, K., Gaie, M., Schensky, A., Gustafson, D.H., Dornelas, E. \& Ahluwalia, J. (2004). Helping adolescents quit smoking: A needs assessment of current and former teen smokers. Health Communication, 16(2), 185-194.

Pinkleton, B.E., Weintraub Austin, E., Cohen, M., Miller, A. \& Fitzgerald, E. (2007). A statewide evaluation of the effectiveness of media literacy training to prevent tobacco use among adolescents. Health Communication, 21(1), 23-24.

Rodgers, A., Corbett, T., Bramley, D., Riddell, T., Wills, M., Lin, R.B. \& Jones, M. (2005). Do u smoke after txt? Results of a randomised trial of smoking cessation using mobile phone text messaging. Tobacco Control, 14(4), 255-261.

Sandhu, S. (2009). Strategic communication: An institutional perspective. International Journal of Strategic Communication, 3(2), 72-92.

Sussman, S., Dent, C.W. \& Lichtman, K.L. (2001). Project EX: Outcomes of a teen smoking cessation program. Addictive Behaviour, 26(3), 425-438.

Sussman, S., Ping, S. \& Dent, C.W. (2006). A meta-analysis of teen cigarette smoking cessation. Health Psychology, 25(5), 549-547.

Tench, R., Verhoeven, P., \& Zerfass, A. (2009). Institutionalising strategic communication in Europe - an ideal home or mad house? Evidence from a Survey in 37 Countries. International Journal of Strategic Communication, 3(2), 147-164.

Tevyaw, T.O'L. (2006, October 1). College student smoking: It's not all smoke and mirrors, The Brown University Digest of Addiction Theory and Application, p. 8.

Wood, J., Wallace, J., Zeffane, R.M., Chapman, J., Fromholtz, M., \& Morrison, V. (2004). Organisational behaviour - a global perspective ( $3^{\text {rd }}$ ed.). Milton, Qld: Wiley.

Zerfass, A., \& Huck, S. (2007). Innovations, communication, and leadership: New developments in strategic communication. International Journal of Strategic Communication, 1(2), 107-122.

Zhao, X., Sayeed, S., Cappella, J., Hornik, R., Fishbein, M. \& Ahern, R.K. (2006). Targeting normrelated beliefs about marijuana use in an adolescent population. Health Communication, 19(3), 187196.

* Jim Mahoney is a Senior Lecturer in Public Relations at the University of Canberra. 